\title{
Impacts of snow on seed germination are independent of seed traits and plant ecological characteristics in a temperate desert of Central Asia
}

\author{
Anlifeire ANNIWAER ${ }^{1,2}$, SU Yangui ${ }^{1}$, ZHOU Xiaobing $^{1}$, ZHANG Yuanming $^{1 *}$ \\ ${ }^{1}$ State Kay Laboratory of Desert and Oasis Ecology, Xinjiang Institute of Ecology and Geography, Chinese Academy of \\ Sciences, Urumqi 830011, China; \\ ${ }^{2}$ University of Chinese Academy of Sciences, Beijing 100049, China
}

\begin{abstract}
Seed germination profoundly impacts plant community composition within the plant life cycle. Snow is an important source of water for seed germination in the temperate deserts of Central Asia. Understanding how seed germination responds to variations in snow cover in relation to seed traits and plant ecological characteristics can help predict plant community sustainability and stability in Central Asia under a scenario climate change. This study investigated the seed germination of 35 plant species common to the Gurbantunggut Desert in Central Asia under the three snow treatments: (1) snow addition; (2) ambient snow; and (3) snow removal. Two-way analysis of variance (ANOVA) tests were performed to assess interactions among the impacts of snow treatments, seed traits and plant ecological characteristics on seed germination. Phylogenetic generalized least-squares (PGLS) model was used to test the relationships between seed traits and seed germination. The results demonstrated that snow variations had no significant impacts on seed germination overall. Seed germination under the snow addition treatment was similar with that under the ambient snow treatment, irrespective of seed traits and plant ecological characteristics. Snow removal only had negative impacts on seed germination for certain groups of seed traits and plant ecological characteristics. Seed mass positively affected seed germination, showing a linear increase of arcsin square root-transformed seed germination with log-transformed seed mass. Seed shape also profoundly impacted seed germination, with a higher germination percentage for elongated and flat seeds. Seed germination differed under different plant life forms, with semi-shrub species showing a significantly higher germination percentage. Most importantly, although snow treatments, seed traits and plant ecological characteristics had no interactive effects on seed germination overall, some negative impacts from the snow removal treatment were detected when seeds were categorized on the basis of seed mass and shape. This result suggests that variations of snow cover may change plant community composition in this temperate desert due to their impacts on seed germination.
\end{abstract}

Keywords: snow cover; seed germination; seed traits; plant life form; Gurbantunggut Desert

Citation: Anlifeire ANNIWAER, SU Yangui, ZHOU Xiaobing, ZHANG Yuanming. 2020. Impacts of snow on seed germination are independent of seed traits and plant ecological characteristics in a temperate desert of Central Asia. Journal of Arid Land, 12(5): 775-790. https://doi.org/10.1007/s40333-020-0059-9

\section{Introduction}

Year-round or seasonal snow cover shows inter-annual variation at high and middle latitudes and

*Corresponding author: ZHANG Yuanming (E-mail: zhangym@ms.xjb.ac.cn)

The first and second authors contributed equally to this work.

Received 2019-08-22; revised 2019-12-12; accepted 2020-05-11

(C) Xinjiang Institute of Ecology and Geography, Chinese Academy of Sciences, Science Press and Springer-Verlag GmbH Germany, part of Springer Nature 2020 
at high altitudes, and the degree of inter-annual variation is increasing, especially under climate change. This change in inter-annual snowfall variation generally leads to changes in soil physical variables, including temperature and water availability, thus affecting the evolution of local ecosystems (Houle, 2002; Decker et al., 2003; Keller et al., 2005). For example, snowfall significantly changes nitrogen uptake by vegetation (Bilbrough, 2000), photosynthesis and respiration rates ( $\mathrm{Li}$ et al., 2006a), biomass accumulation (Dorrepaal et al., 2004) and biomass allocation (Kreyling et al., 2012; Chen et al., 2013). Earlier germination and completion of the life cycle of spring ephemerals under increasing snow enhance their competitive advantage in a plant community in North America (Houle, 2002). Early spring ephemerals in Central Asia have adapted to arid deserts by evolving a short-term growth rhythm and specific biological traits (Lapointe et al., 2006; Constable et al., 2007). Therefore, changes in snowfall may affect seed germination and seedling survival of plant species in this region (Chao and Sun, 2016; Jia et al., 2017). Similarly, the responses of seed germination to snow vary according to plant functional group in the Great Lakes region of North America (Drescher and Thomas, 2013).

Seed germination is a critical stage of the plant life cycle and determines subsequent plant performance and survival, ultimately affecting plant community composition. Seed germination has been associated with various seed biological traits, including seed size, mass and shape. In addition, plant ecological characteristics have been recognized as a key factor influencing seed germination. Seed size is an important ecological feature of plant life history, which can affect the life history characteristics of plant seedling survival, seed spread and seed numbers (Westoby et al., 1992; Frenner, 2000). Lorenzi et al. (2002) studied 169 tree species in a tropical rainforest of Brazil and found a significant positive correlation between seed size and average germination time. Studies of 558 plant species in the alpine region of the Qinghai-Tibet Plateau and 69 species of mesophytes in the Hexi Corridor of China showed that seed size was an important determinant of plant life history characteristics (Liu et al., 2003, 2004; Li et al., 2006b; Bu et al., 2008; Wang, 2009). The relationship between seed size and seed germination remains contentious, with some studies showing a significant negative correlation and others showing no significant relationship (Liu et al., 2007).

Seed mass is one of the most important seed biological traits and contributes to different levels of seed germination as the amounts of starch and endosperm nutrients contained in a seed may determine the energy and nutrients available for seed germination (Chen et al., 2002; Soriano et al., 2011). Studies have shown that seed mass may affect seed germination (Reich, 1994; Paz et al., 1999; Bu et al., 2007; Xu et al., 2014). Direct positive experimental evidences of the impacts of seed mass on seed germination remain scarce, and mostly relate to positive impacts on seed germination (Catoni et al., 2015; Wang et al., 2016) and seedling survival (Wang, 2009). However, indirect evidence has shown that seed size is positively related to seed germination $(\mathrm{Bu}$ et al., 2007; Wang et al., 2009). Whether seed mass is also positively related to seed germination remains unclear. Seed shape is another important trait that influences seed germination (Weiher et al., 1999; Tekrony et al., 2005). Although theoretical studies have predicted that elongated and flat seeds should exhibit a higher germination percentage (GP) compared to round seeds (Gremer et al., 2014), experimental evidence is needed to understand the role of seed shape in seed germination (Liu et al., 2014).

Precipitation variation is a crucial component of global climate change, and studies of the plant growing season have demonstrated the impacts of changing patterns of precipitation on ecosystems. Increased precipitation has been shown to significantly increase (Zheng et al., 2005; Arfin-Khan et al., 2018), decrease (Zhao et al., 2012) or have no impact on (Weltzin and Mcpherson, 2000) seedling emergence percentage (i.e., GP). Snow is an important source of water for seed germination and seedling survival in most parts of the temperate deserts in Central Asia. Snow melt provides the moisture necessary for seed germination and plant growth during early spring (Gutterman, 2000; Sun et al., 2009; Yuan and Tang, 2010; Fan et al., 2013). Previous studies have shown that variations in snow cover have profound impacts on herbaceous plant community composition at the peak of plant growth. While studies on invasive and indigenous plants have shown that an increase or decrease in snow cover has no significant impact on seed 
germination, but an increase in snow cover is beneficial to the establishment of indigenous plant populations (Gornish et al., 2015).

Seed germination is an important factor affecting plant community composition, and studies exploring the relationship between variations in snow cover and seed germination of various species can improve understanding of plant community composition and stability in the temperate deserts in Central Asia under climate change. For example, the number of snowfall days has been shown to affect the wintering safety of Pinus sylvestris var. mongolica seedlings (Yan et al., 2012). Decreased snow may result in the loss of the snow-cover temperature barrier, thereby decreasing the probability of survival over winter for many plant species (Simons et al., 2010). Snow cover is essential to seed germination because of its direct impacts on water availability and indirect impacts on soil temperature and nutrient availability. For instance, the replenishment of soil moisture during early spring in a desert ecosystem could increase soil water content (SWC) (Fan et al., 2012). Changes in soil physical properties may have different impacts on seed germination in terms of plant ecotype and seed traits, thus changing plant community composition and succession (Drescher and Thomas, 2013).

The present study aims to assess the impacts of snow and seed traits (or plant ecological characteristics) on seed germination by investigating the seed germination characteristics of 35 plant species common to the Gurbantunggut Desert in Central Asia under the three snow treatments (snow addition, ambient snow and snow removal). The 35 plant species show a wide range of variation in terms of seed mass, shape and color, and also have different plant ecological traits. A previous study conducted $150 \mathrm{~km}$ away from the study site of the present study demonstrated that a $50 \%$ increase in snow cover profoundly decreased spring ephemeral density in one year out of three consecutive years studied, whereas a $100 \%$ increase in snow cover exerted no impacts on spring ephemeral density (Fan et al., 2014). The seeds of spring ephemerals are characterized by a small size and a low mass; therefore, they may require less water to promote germination compared with large seeds. The change of snow cover has a profound effect on the composition of the herbaceous plant community during the period of vigorous growth. Seed germination is one of the important factors that affect the composition of plant communities. Therefore, under a scenario of climate change, studying how snow cover affects seed germination is helpful to understand the composition and stability of desert plant communities in the temperate deserts of Central Asia.

\section{Materials and methods}

\subsection{Study area}

The Gurbantunggut Desert is located in southeast of Central Asia and has a climate and plant composition typical of the temperate deserts of Central Asia. This temperate desert exhibits an annual precipitation varying from 70 to $160 \mathrm{~mm}$, with most precipitation occurring during spring. There is snow cover from early November to late March, ranging from 10 to $50 \mathrm{~cm}$ in thickness, with a mean annual of $30 \mathrm{~cm}$. The mean annual potential evaporation is $2606 \mathrm{~mm}$. The annual mean temperature is $7^{\circ} \mathrm{C}$, with the minimum of $-40^{\circ} \mathrm{C}$ and a mean of $-17^{\circ} \mathrm{C}$ in January. Plant community in the desert is composed of semi-shrubs, spring ephemerals, spring-summer annuals and perennial herbs (Huang et al., 2015). Semi-shrubs in the region, such as Haloxylon ammodendron, Haloxylon persicum and Tamarix ramosissima, depend primarily on groundwater to survive. Although these plants fall their leaves in October, their above-ground woody parts persist through the winter. Spring ephemerals, such as Erodium oxyrrhynchum, Alyssum linifolium, Schismus arabicus and Lactuca undulate, generally depend on snowmelt water and spring precipitation for growth (Fan et al., 2014; Huang and Li, 2015). In contrast, spring-summer annuals and perennial herbs, such as Salsola subcrassa, Ceratocarpus arenarius, Seriphidium santolinum and Agriophyllum squarrosum, depend on summer precipitation as their main source of water (Huang et al., 2015). Spring-summer annuals often show low growth rates during the growing season of ephemerals, with their growth rates accelerating after ephemerals die (Huang 
et al., 2018). A new non-woody shoot emerges from perennial herbs every April that persists until the onset of autumn (i.e., October). Soils of the region are desert solonetz, with aeolian sandy soil on the top layer $(0-100 \mathrm{~cm})$. Up to 206 plant species are found in this desert (Zhang and Chen, 2002), and plant community composition changes noticeably from the edge to the center of the desert due to varying soil moisture and soil texture.

\subsection{Experimental design}

The experiments were performed in the center of the Gurbantunggut Desert $\left(45^{\circ} 14^{\prime} \mathrm{N}, 87^{\circ} 36^{\prime} \mathrm{E}\right)$, and an experimental approach was used to test the impacts of snow addition and removal on seed germination. A relatively uniform interdunal area was selected and divided into 15 plots (each area of $3 \mathrm{~m} \times 3 \mathrm{~m}$ ), which were randomly allocated among the three treatments: (1) snow addition; (2) ambient snow; and (3) snow removal. Each snow treatment had five replicates. Frames (1.5 $\mathrm{m} \times 3.0 \mathrm{~m})$ covered with a transparent polycarbonate sheets were installed on the snow removal plots. The sheets were $1.5 \mathrm{~mm}$ thick and allowed $92 \%$ of photosynthetically-active radiation to pass through onto the plots. The plots were surrounded by snow nets to avoid the accumulation of snow. The polycarbonate frames were supported by steel and rebar scaffolding tethered to the ground and rising to a height of $30 \mathrm{~cm}$ above the soil surface. After each snowfall event, we increased or decreased the snow cover of each treatment according to the extent of the last snowfall event. For the snow removal plots, snow was removed from the transparent polycarbonate coverings on each plot after each snowfall event. Ambient snow plots were left to receive natural snowfall. The snow removed from the snow removal plots was evenly sprinkled to the snow addition plots. Shade netting was wrapped around the frame since mid-October to prevent wind-blown snow from entering the plots, and was removed after snowmelt in late March. In addition, the plants in the plots were relatively uniformly distributed.

\subsection{Soil water content (SWC) and soil temperature measurements}

EM50 data loggers equipped with 5TE (Decagon Devices, Pullman, Washington, USA) were positioned within the $2 \mathrm{~cm}$ soil layer within a designated instrument subplot in each plot before winter to measure volumetric SWC and soil temperature. Measurements were taken at $15 \mathrm{~min}$ intervals from October to April in 2015-2016 using the EM50 data loggers.

\subsection{Seed collection}

Mature seeds of 35 investigated species inhabiting different sites across the desert were collected at the time of seed dispersal from mid-May to late October, 2015. Seeds were collected from at least 25 plants for each species, and then they were thoroughly mixed to minimize the risk of a single plant dominated the seed collection. Air dried seeds were stored in paper bags in the laboratory for further processing.

\subsection{Field and laboratory germination experiments}

For each species, five replicates of 100 seeds were placed in fiberglass mesh bags $(25 \mathrm{~cm} \times 25 \mathrm{~cm})$. The grid mesh of the bags was $1.2 \mathrm{~mm}$ on the upper surface and $0.1 \mathrm{~mm}$ on the lower surface, which allowed seeds to access soil by passing roots through the lower surface while at the same time protecting the seeds from micro-invertebrate predation. We randomly buried one bag for each species to a soil depth of $1-3 \mathrm{~cm}$ according to seed mass and shape variance to ensure seeds remained in contact with bulk soil and to facilitate the complete recovery of all seeds (Abbott and Roundy, 2003) in each plot in mid-October, 2015, prior to the first snowfall. On 21 April 2016, seeds with a radicle present at the time of harvest were marked for germination and counted. The remaining seeds were transported to the laboratory for further germination experiments. In the laboratory, non-germinated seeds were placed on filter paper in Petri dishes ( $9 \mathrm{~cm}$ in diameter) and the filter paper was moistened with distilled water. Controlled laboratory conditions with a mean temperature of $20^{\circ} \mathrm{C}$ and natural light were maintained. Each Petri dish was inspected daily, and germinated seeds were counted and removed. The seeds in which the radicles had emerged were considered to have germinated. Counting continued until no germination occurred for five successive days. During the laboratory experiment, germinated seeds were considered as 
non-dormant, and non-germinated seeds at harvest or seeds that were decomposed were scored as dead. The GP was calculated in two forms: (1) field germinated seeds divided by the total number of experimental seeds (100 seeds; GP-1); and (2) field germinated seeds divided by the sum of field germinated seeds and laboratory germinated seeds (GP-2). Of the two measures, GP-1 reflected the impacts of snow on real seed germination at a species level, whereas GP-2 can be used to indicate the seed germination rate as affected by snow variation and rainfall in the coming seasons.

\subsection{Seed traits and plant ecological characteristics}

A group of 100 air-dried seeds of each species was weighed using a fine balance (FA1604N, Jinghong, Shanghai, China; accuracy to $0.0001 \mathrm{~g}$ ), with five replicates per species (Thompson et al., 1993). The mean seed mass was classified into six classes (Moles et al., 2000): (1) <20 mg; (2) 20-50 mg; (3) 50-100 mg; (4) 100-200 mg; (5) 200-500 mg; and (6) >500 mg.

The seed shape was calculated as the variance of the three main perpendicular dimensions after dividing all values by the length. These seed shape values ranged from 0.00 for spherical seeds to 0.33 for elongated or flat seeds (Thompson et al., 1993). In the present study, we categorized the seeds into four grades based on seed shape (Liu, 1992; Gordon, 1998; Liu et al., 2005; Liu et al., 2014): (1) <0.05; (2) 0.05-0.10; (3) 0.10-0.15; and (4) $>0.15$.

In this study, we classified the species into five color categories based on observations and relevant literature (Liu, 1992; Gordon, 1998; Liu et al., 2005; Liu et al., 2014): (1) white; (2) yellow (pale yellow or yellow); (3) green (yellowish green or brownish green); (4) brown (light yellowish brown, light reddish brown, brown, dark brown, yellowish brown or reddish brown); and (5) black.

We also grouped the species into four classes based on the plant life form: (1) semi-shrubs; (2) spring ephemerals; (3) spring-summer annuals; and (4) perennial herbs. Moreover, we assigned the species to two kinds of plant ecotypes based on the seed collection sites: (1) mesophyte; and (2) xerophyte.

Following the study of Zanne et al. (2014), we built a phylogenetic tree using the online software Phylomatic (Webb and Donoghue, 2005) based on the Angiosperm Phylogeny Group (APG) III consensus topology (Fig. 1).

\subsection{Tests of seed viability}

Seed viability after germination was assessed using a tetrazolium test (Hendry et al., 1993). Seeds with strong red-stained embryos were considered in the test. At the end of the germination tests, the viability of non-germinated seeds was examined through dissection using a needle to determine the presence of a firm embryo (Baskin et al., 2000).

\subsection{Statistical analysis}

All statistical analyses were performed using R software v4.0.0 (R Core Team 2020; Vienna, Austria) and SPSS 16.0 software (SPSS Inc., Chicago, IL, USA), and all continuous variables were log-transformed. Two-way analysis of variance (ANOVA) tests were performed to assess the correlations of snow treatments (snow addition, ambient snow and snow removal) with seed traits (seed mass, shape and color) and plant ecological characteristics (plant life form and ecotype). Dichotomized APG III phylogenetic trees were created using the multi2di function in the ape package in $\mathrm{R}$ software. Blomberg $k$ values (Blomberg et al., 2003) were estimated by means of the Kcalc function of the picante package in $\mathrm{R}$ software. Phylogenetic generalized least-squares (PGLS) model was constructed in the R package nlme (Pinheiro et al., 2019), incorporating Pagel's (Pagel et al., 1999) phylogenetic correlation structure (corPagel) as implemented in the ape package to estimate the phylogenetic scaling parameter $\lambda$ using maximum likelihood. The fit of these models was then compared with that of models which had $\lambda$ fixed to either 0 (phylogenetic independence) or 1 (complete phylogenetic association). A Brownian correlation structure (corBrownian) was used for Pearson's product-moment correlations among seed traits (Paradis et al., 2004). 

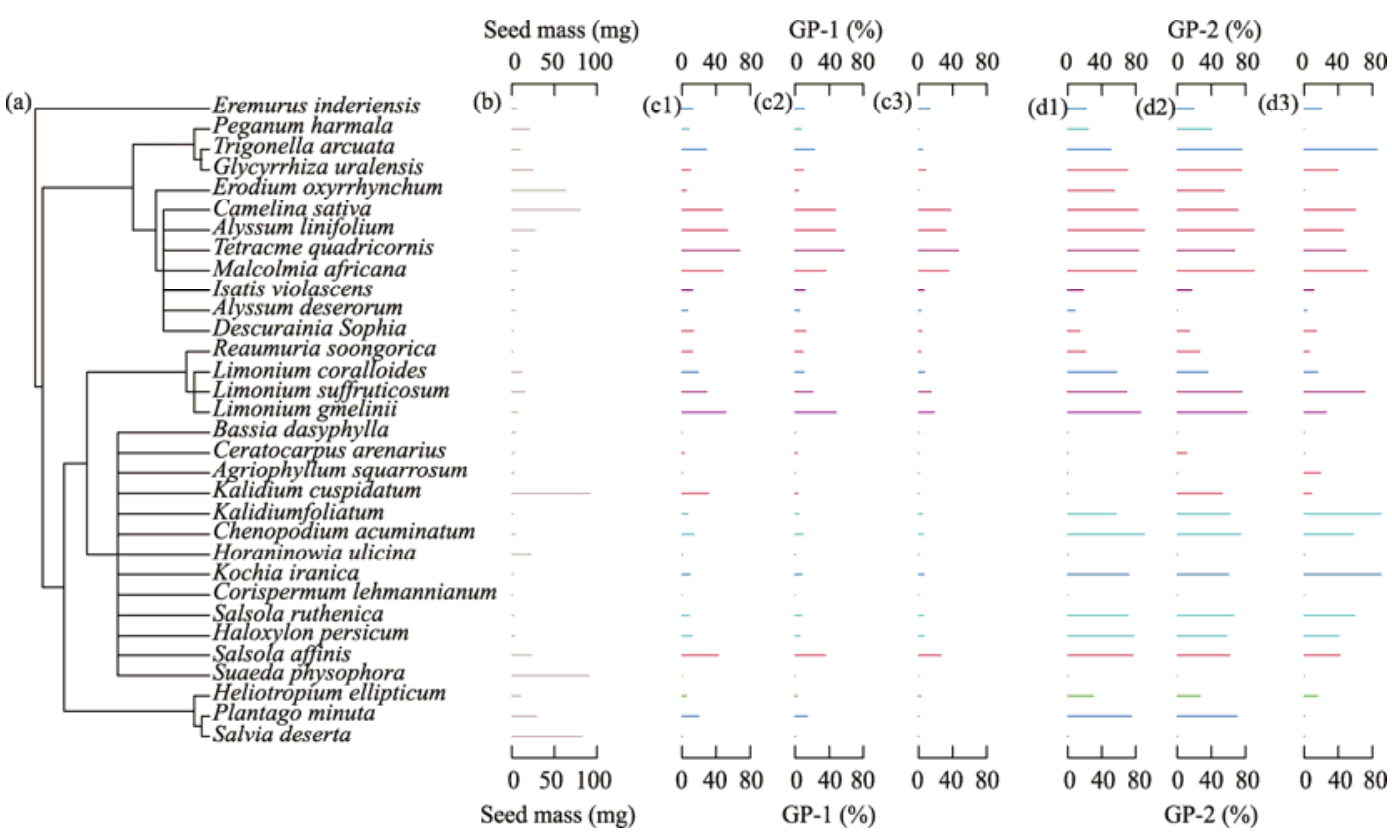

Fig. 1 Phylogenetic position of the selected 35 species (a), seed mass (b), GP-1 (c1, c2 and c3) and GP-2 (d1, d2 and $\mathrm{d} 3$ ) under the snow addition ( $\mathrm{c} 1$ and $\mathrm{d} 1)$, ambient snow (c2 and $\mathrm{d} 2$ ) and snow removal (c3 and $\mathrm{d} 3)$ treatments. Different color lines indicate different dispersal modes (red for anemochory, light blue for autochory, dark blue for barochory, green for ombrohydrochory, and pink for zoochory). GP-1 and GP-2 represent two forms of germination percentage (GP). GP-1 was calculated as field germinated seeds divided by the total number of experimental seeds and GP-2 was calculated as field germinated seeds divided by the sum of field germinated seeds and laboratory germinated seeds. We built the phylogenetic tree according to the study of Zanne et al. (2014).

\section{Results}

\subsection{Snow impacts on SWC and soil temperature}

There were significant differences in SWC (the volume of water per volume of soil; \%) among the three snow treatments (Fig. 2a). In general, SWC tended to decrease during the winter months in the surface $2 \mathrm{~cm}$ soil layer under all snow treatments because of reduced water use by vegetation. SWC increased sharply from February under the ambient snow and snow addition treatments. There was no difference in soil temperature among the three snow treatments (Fig. 2b).
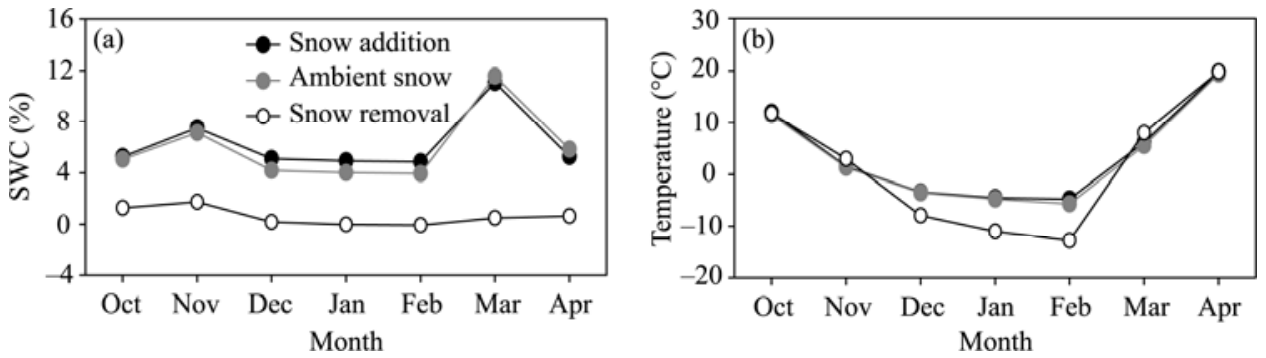

Fig. 2 Comparison of volumetric soil water content (SWC; a) and soil temperature (b) in the surface $2 \mathrm{~cm}$ soil layer under the snow addition, ambient snow and snow removal treatments from October to April

\subsection{Snow impacts on seed germination}

In general, snow variations had no significant impacts on seed germination for the selected 35 species in the Gurbantunggut Desert $(P=0.265$; Table 1). No significant interactions were found between snow treatments and seed traits (seed mass, shape and color) in the present study $(P>0.05$; Table 1). Moreover, snow exhibited no significant interaction with plant ecological characteristics (plant life form and ecotype) that would affect seed germination $(P>0.05$; Table 1$)$. 
Table 1 Results of two-way analysis of variance (ANOVA) of snow in relation to seed traits (seed mass, shape and color) and plant ecological characteristics (plant life form and ecotype) on seed germination

\begin{tabular}{|c|c|c|c|c|c|}
\hline \multirow{2}{*}{ Source of variation } & \multirow{2}{*}{$d f$} & \multicolumn{2}{|c|}{ GP-1 } & \multicolumn{2}{|c|}{ GP-2 } \\
\hline & & $F$ & $P$ & $F$ & $P$ \\
\hline Snow & 2 & 1.346 & 0.265 & 1.892 & 0.156 \\
\hline Snow $\times$ seed mass & 10 & 0.157 & 0.998 & 0.392 & 0.947 \\
\hline Snow $\times$ seed shape & 6 & 0.848 & 0.536 & 0.353 & 0.907 \\
\hline Snow $\times$ seed color & 8 & 0.047 & 1.000 & 0.261 & 0.977 \\
\hline Snow $\times$ plant life form & 6 & 0.291 & 0.967 & 0.111 & 0.999 \\
\hline Snow $\times$ plant ecotype & 2 & 0.078 & 0.925 & 0.083 & 0.921 \\
\hline
\end{tabular}

Note: GP-1 and GP-2 represent two forms of germination percentage (GP). GP-1 was calculated as field germinated seeds divided by the total number of experimental seeds and GP-2 was calculated as field germinated seeds divided by the sum of field germinated seeds and laboratory germinated seeds. $d f$, degree of freedom.

\subsection{Seed traits impacts on seed germination}

There was a significantly positive influence of seed mass on seed germination $(P<0.01$; Fig. 3$)$. For GP-1, the arcsine square root-transformed seed germination increased linearly with the log-transformed seed mass, with the slopes of these regressions differing significantly between the snow addition and ambient snow treatments $(P=0.01$; Fig. 3a). Similarly, the slope of the regression for the snow removal treatment was significantly lower than that of the ambient snow treatment $(P=0.02$; Fig. 3a). Snow addition and snow removal treatments exerted no significant impacts on the intercepts of the linear regressions compared with the ambient snow treatment $(P>0.05$; Fig. 3). For GP-2, the arcsine square root-transformed seed germination was positively related to the log-transformed seed mass under the snow addition and ambient snow treatments, and negatively correlated to the log-transformed seed mass under the snow removal treatment (Fig. 3b). The slopes and intercepts of the regressions under both the snow addition and snow removal treatments were not significantly different to those of the ambient snow treatment $(P>0.05$; Fig. 3b).
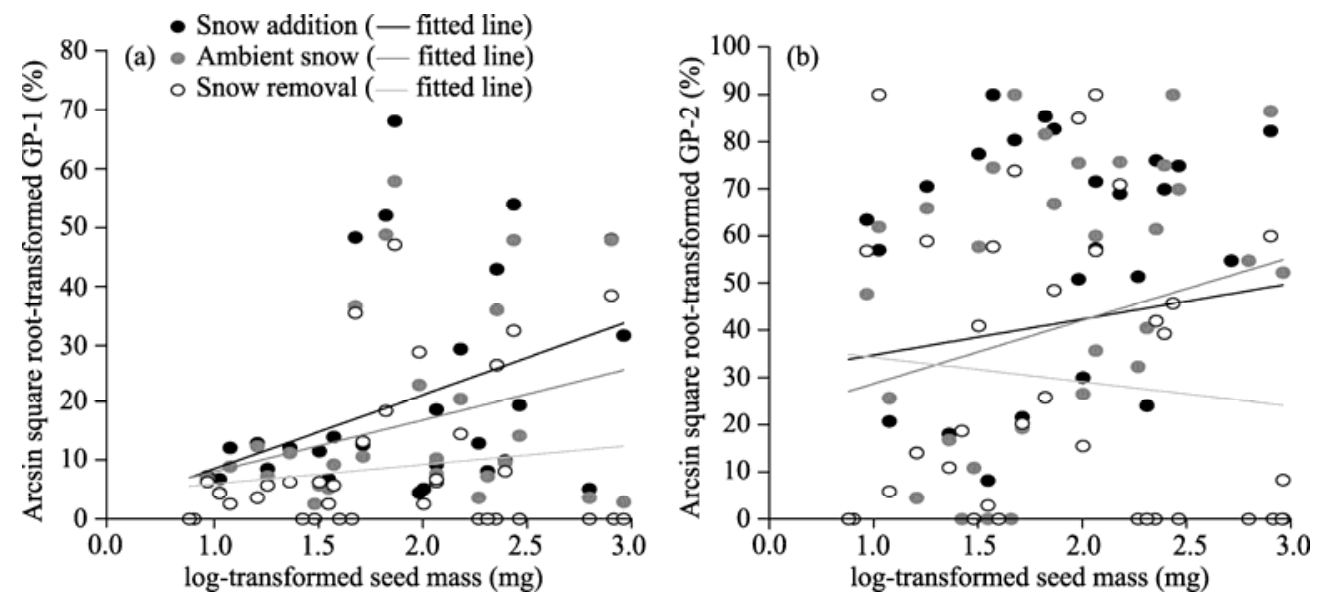

Fig. 3 Linear relationships between log-transformed seed mass and arcsine square root-transformed GP-1 (a) and between log-transformed seed mass and arcsine square root-transformed GP-2 (b) under the snow addition, ambient snow and snow removal treatments. Slope differences among ambient snow, snow addition and snow removal treatments were analyzed by the two-way analysis of variance (ANCOVA) analysis.

Elongated or flat seeds exhibited the highest GP (Fig. 4). Snow removal treatment significantly decreased GP-1 with a seed shape variance higher than 0.05 , while GP-1 was similar between the snow addition and ambient snow treatments (Fig. 4a). For GP-2, snow removal treatment profoundly inhibited seed germination with seed shape variance values of $0.05-0.10$ and $\geq 0.15$ (Fig. 4b), whereas snow addition treatment exerted no impacts on seed germination compared with the ambient snow treatment (Fig. 4b). 

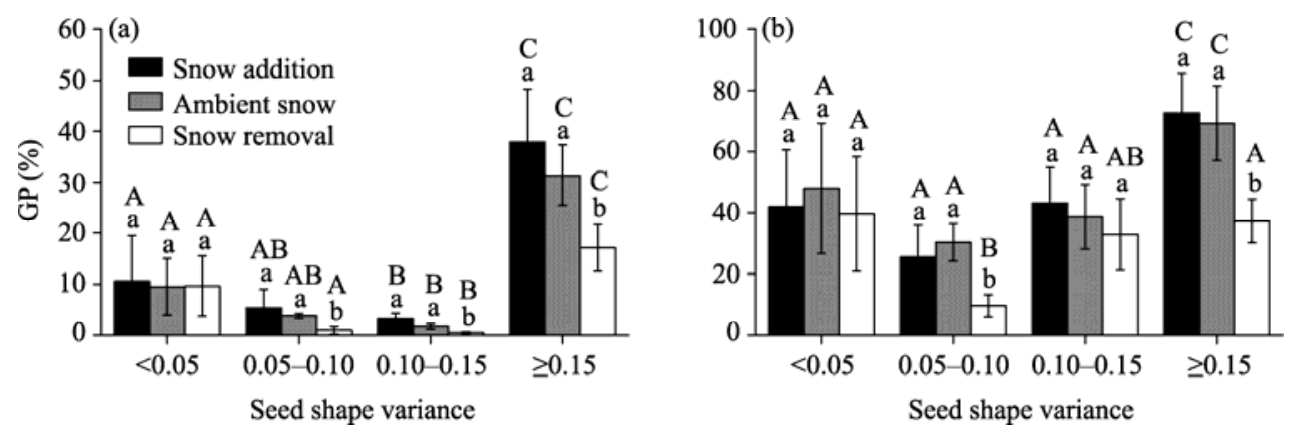

Fig. 4 Seed germination percentage (GP) influenced by seed shape variance under the snow addition, ambient snow and snow removal treatments for GP-1 (a) and GP-2 (b). Different lowercase letters indicate significant differences among the three snow treatments within a level of seed shape variance at $P<0.05$ level; different uppercase letters indicate significant differences among different levels of seed shape variance within the same snow treatment at $P<0.05$ level.

Seeds with a green seed coat exhibited the highest GP-1 for all the three snow treatments, with white, yellow and black seeds showing a similar low germination (Fig. 5a). White seeds showed a significantly stronger response to snow addition or removal treatment compared to the other seeds. Black seeds showed the lowest GP-2 compared with the other seeds (Fig. 5b). Snow addition treatment had no effect on GP-2 of any colored seeds, and snow removal treatment only reduced the GP-2 of brown seeds.
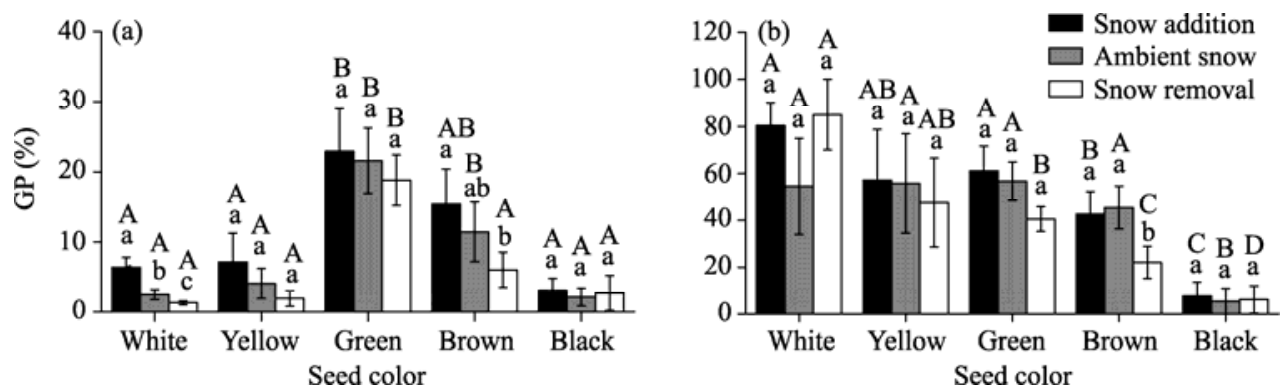

Fig. 5 Seed GP influenced by seed color under the snow addition, ambient snow and snow removal treatments for GP-1 (a) and GP-2 (b). The number of replicates $(n)$ is different among different colors of seeds, i.e., $n=3$ for white seeds, $n=15$ for yellow seeds, $n=15$ for green seeds, $n=69$ for brown seeds, and $n=6$ for black seeds. Different lowercase letters indicate significant differences among the three snow treatments within the same seed color at $P<0.05$ level; different uppercase letters indicate significant differences among different seed colors within the same snow treatment at $P<0.05$ level. Yellow color includes pale yellow or yellow; green color includes yellowish green or brownish green; brown color includes light yellowish brown, light reddish brown, brown, dark brown, yellowish brown or reddish brown.

\subsection{Plant life form impacts on seed germination}

Plant life form significantly affected GP-1 and GP-2 (Fig. 6). The seeds of semi-shrubs exhibited the highest GP-1, and similar GP-1 values were observed among perennial herbs, spring-summer annuals and spring ephemerals (Fig. 6). GP-1 values were similar between the snow addition and ambient snow treatments, irrespective of plant life form, whereas they were lower under the snow removal treatment for semi-shrubs and spring-summer annuals compared with the ambient snow treatment (Fig. 6a). Although GP-2 values of semi-shrubs were much higher than those of perennial herbs and spring-summer annuals, they were similar among perennial herbs, spring-summer annuals and spring ephemerals (Fig. 6b). GP-2 values were similar between the snow addition and ambient snow treatments, irrespective of plant life form. Snow removal treatment resulted in a significant decrease in the seed germination of semi-shrubs, whereas it exerted no impacts on other plant life forms (Fig. 6b).

Plant ecotype had no impacts on GP-1 and GP-2 (Table 1). GP-2 in the mesophyte ecotone was 
significantly higher than that in the xerophyte ecotone (Fig. 7). Snow addition and snow removal treatments exhibited no impacts on GP-1 and GP-2, irrespective of plant ecotype (Fig. 7).
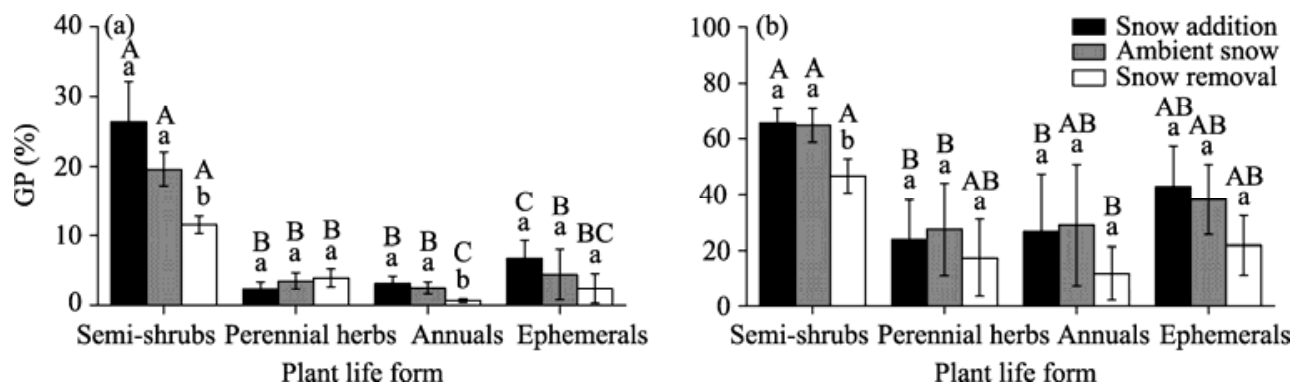

Fig. 6 Seed GP influenced by plant life form under the snow addition, ambient snow and snow removal treatments for GP-1 (a) and GP-2 (b). Different lowercase letters indicate significant differences among the three snow treatments within the same plant life form at $P<0.05$ level; different uppercase letters indicate significant differences among different plant life forms within the same snow treatment at $P<0.05$.
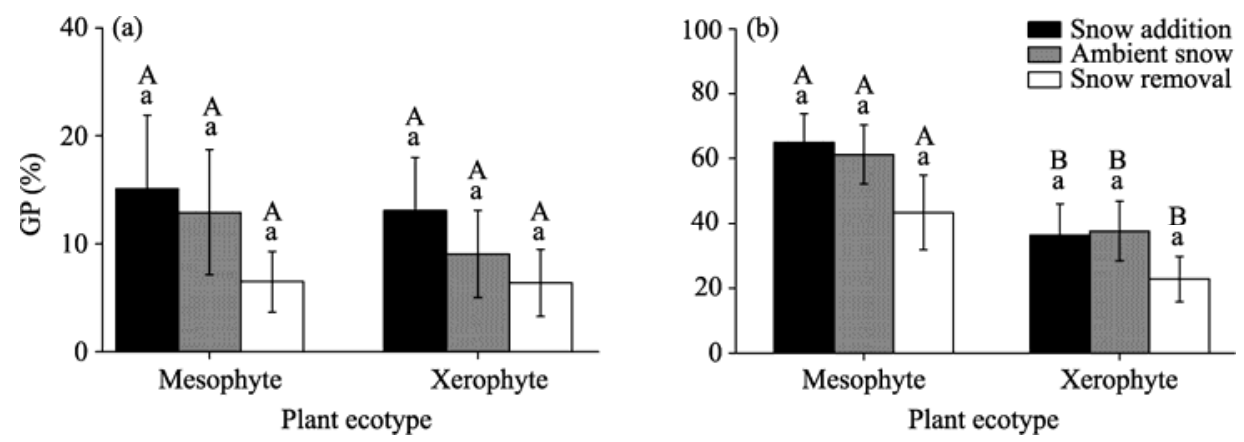

Fig. 7 Seed GP influenced by plant ecotype under the snow addition, ambient snow and snow removal treatments for GP-1 (a) and GP-2 (b). Different lowercase letters indicate significant differences among the three snow treatments within the same plant ecotype at $P<0.05$ level; different uppercase letters indicate significant differences between the two plant ecotypes within the same snow treatment at $P<0.05$ level.

\subsection{Correlations between seed traits and seed germination}

The relationships of seed germination with both seed mass and seed shape variance were better described by the PGLS models, with a higher phylogenetic signal occurring in the snow removal treatment ( $k=0.40$ for GP-1 and $k=0.63$ for GP-2) than in the ambient snow ( $k=0.40$ for GP-1 and $k=0.38$ for GP-2) and snow addition ( $k=0.38$ for GP-1 and $k=0.55$ for GP-2) treatments. In most cases, the PGLS models provided a significantly better fit to the data than the generalized least-squares (GLS) models (Figs. 8 and 9). Seed traits were also correlated with GP-1, in which heavy and elongated and flat seeds showed a higher GP under the snow removal treatment (Figs. 8 and 9; Table 2). Variance in seed shape did not show any significant correlations with GP-2 (Fig. 9; Table 2).

\section{Discussion}

Snow treatment in general had no significant impacts on seed germination, and the snow addition treatment did not significantly increase seed germination, irrespective of seed traits and plant ecological characteristics. The snow removal treatment exerted negative impacts only on seed germination within certain groups of seed traits and plant ecological characteristics. This result contradicts the current study that snow addition and removal would exert positive and negative impacts on seed germination, respectively. Seed traits, including seed mass, shape and color, had significant impacts on GP of seeds, as did plant life form. The influences of plant ecotype on seed 

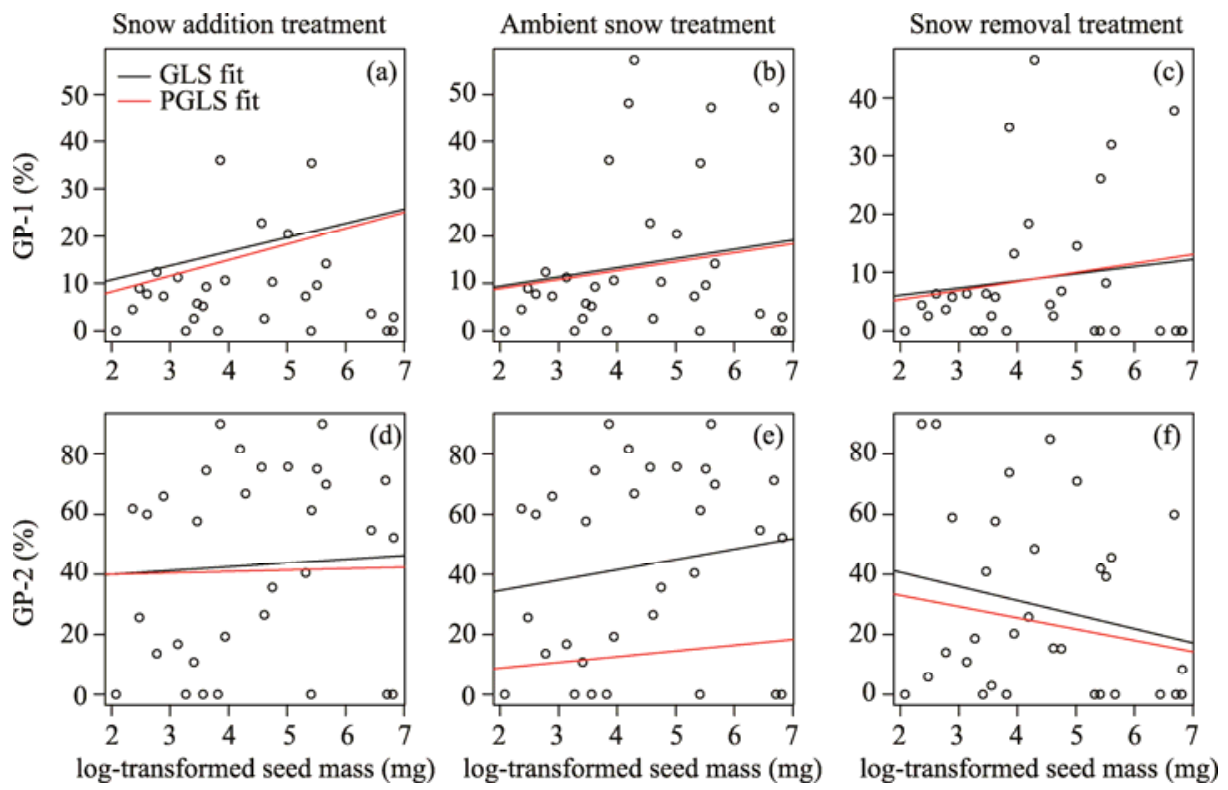

Fig. 8 Relationships of log-transformed seed mass with GP-1 (a-c) and GP-2 (d-f) described by the phylogenetic generalized least-squares (PGLS) models and generalized least-squares (GLS) models under the snow addition $(\mathrm{a}, \mathrm{d})$, ambient snow $(\mathrm{b}, \mathrm{e})$ and snow removal $(\mathrm{c}, \mathrm{f})$ treatments
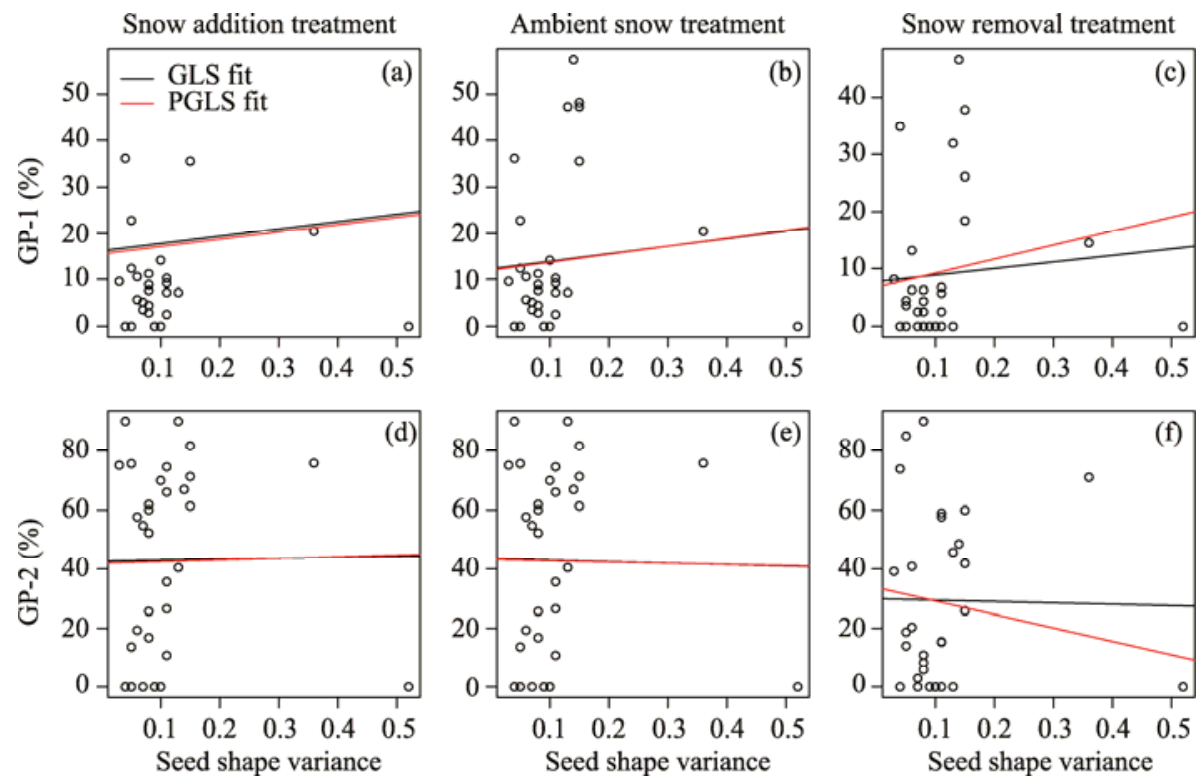

Fig. 9 Relationships of seed shape variance with GP-1 (a-c) GP-2 (d-f) described by the PGLS models and GLS models under the snow addition (a, d), ambient snow (b, e) and snow removal (c, f) treatments

germination were only significant for GP-1. Moreover, the impacts of seed traits and plant ecological characteristics on seed germination were independent of snow treatments. The results of the present study clearly showed that phylogenetic groups significantly influenced seed germination for the plant species in the Gurbantunggut Desert. These results are supported by previous research, which showed that seed germination was correlated with plant phylogeny in the temperate rain forests (Figueroa, 2003) and alpine meadows (Bu et al., 2007; Xu et al., 2014) in arid and semi-arid zones. We therefore proposed in the current study that variation in seed germination is closely dependent on the phylogeny. 
Table 2 Results of the phylogenetic generalized least-squares (PGLS) models examining the impacts of seed traits (seed mass and seed shape variance) on GP (GP-1 and GP-2) under the snow addition, ambient snow and snow removal treatments

\begin{tabular}{|c|c|c|c|c|c|c|c|c|}
\hline Response & $Y$ & $X$ & Slope & SD & $t$ & $P$ & $r$ & $\lambda$ \\
\hline \multirow[t]{3}{*}{ GP-1 } & Snow addition & Seed mass $(\log 10)$ & 3.365 & 2.088 & 1.611 & 0.117 & 0.313 & 0.722 \\
\hline & Ambient snow & Seed mass $(\log 10)$ & 1.896 & 1.828 & 1.037 & 0.308 & 0.169 & 0.728 \\
\hline & Snow removal & Seed mass $(\log 10)$ & 1.544 & 1.313 & 1.175 & 0.248 & 0.201 & 0.940 \\
\hline \multirow[t]{3}{*}{ GP-2 } & Snow addition & Seed mass $(\log 10)$ & 2.960 & 66.212 & 0.044 & 0.964 & -0.075 & 0.000 \\
\hline & Ambient snow & Seed mass $(\log 10)$ & 1.896 & 1.828 & 1.037 & 0.308 & 0.054 & 0.728 \\
\hline & Snow removal & Seed mass $(\log 10)$ & -4.683 & 3.800 & -1.232 & 0.227 & -0.253 & 0.000 \\
\hline \multirow[t]{3}{*}{ GP-1 } & Snow addition & Seed shape variance & 15.863 & 34.576 & 0.458 & 0.649 & 0.063 & 0.612 \\
\hline & Ambient snow & Seed shape variance & 17.239 & 29.495 & 0.584 & 0.563 & 0.071 & 0.709 \\
\hline & Snow removal & Seed shape variance & 24.552 & 21.199 & 1.158 & 0.255 & 0.198 & 1.000 \\
\hline \multirow[t]{3}{*}{ GP-2 } & Snow addition & Seed shape variance & 2.960 & 66.212 & 0.044 & 0.964 & -0.048 & 0.000 \\
\hline & Ambient snow & Seed shape variance & -4.870 & 60.795 & -0.080 & 0.936 & -0.030 & 0.000 \\
\hline & Snow removal & Seed shape variance & -4.569 & 58.389 & -0.078 & 0.938 & 0.152 & 0.000 \\
\hline
\end{tabular}

Note: SD, standard deviation; $t$, test statistic regression; $P$, significance level; $r$, Pearson's correlation coefficient; $\lambda$, phylogenetic correlation coefficient.

\subsection{Interactions between seed traits and plant ecological characteristics under the three snow treatments}

Few researches have focused on the impacts of variations in snow cover on seed germination, with some studies showing that snow impacts on seed germination are dependent on the species under investigation (Drescher, 2014; Gornish et al., 2015). For instance, although snow removal decreased seed germination of both native Pseudoroegnaria spicata and invasive Bromus tectorum grass species in a cold desert in North America, snow addition had no associated impacts (Gornish et al., 2015). Consistent with these studies, the present study exhibited no impacts of snow addition on seed germination for the 35 plant species examined, and snow removal impacts on seed germination were only observed for plants with certain seed traits or plant life forms. This result suggests that the impacts of snow removal on seed germination are depend on the biological traits of a plant species.

The addition of snow can increase SWC and decrease variation in soil temperature, as well as alter the soil freeze-thaw cycles, resulting in increased susceptibility of seeds to soil pathogens and decreased germination of seeds. Soil surface temperatures under the snow addition and ambient snow treatments were similar throughout the experiment in the present study. Moreover, SWC at the depth of $2 \mathrm{~cm}$ showed no differences from snow melting to the time of seed germination. These results suggest that the similar seed germination observed between the ambient snow and snow addition treatments may be due to there being no significant differences in soil temperature and moisture between the two snow treatments. Snow removal treatment dramatically decreased the soil surface temperature and reduced the frequency of the soil freeze-thaw cycles. Moreover, since SWC at snow melt was significantly lower than that ambient snow, the similarity in seed germination between the ambient snow and snow removal treatments may be due to the sufficient spring precipitation experienced during the study period.

The impacts of snow on seed germination are independent of seed traits and plant ecological characteristics in the study area. Snow addition and snow removal treatments significantly changed the slopes of linear regressions between arcsine square root-transformed seed germination and log-transformed seed mass, while there were no differences between the intercepts of regressions, suggesting that the snow treatments had the greatest impacts on heavy seeds. The impacts of both snow addition and snow removal treatments increased with increasing seed mass.

\subsection{Impacts of seed traits and plant ecological characteristics on seed germination}

Several studies have indicated that seed germination is correlated with seed traits such as seed 
shape and mass (Wang et al., 2016). The results of the present study clearly showed that seed traits such as seed mass and shape significantly affected seed germination. In the present study, seed mass positively affected seed germination, which is consistent with the results of many previous studies, which showed that large and heavy seeds have a higher percentage of germination because of their larger reserves of energy and nutrients (van Mölken et al., 2005; Wu and $\mathrm{Du}, 2007$; Galíndez et al., 2009). However, some studies have identified negative relationships between seed mass and seed germination in some semi-arid ecosystems. There are several possible interpretations for this contradiction among studies. The different relationships between seed germination and seed mass are primarily related to the ranges of seed mass investigated among different studies (Grime et al., 1981; van Mölken et al., 2005; Galindez et al., 2009; Wang et al., 2016). For instance, for Tragopogon pratensis species in variable habitats, a study of seed mass ranging from 0.011 to $130.700 \mathrm{mg}$ showed a negative relationship between seed germination and seed mass (Wang et al., 2016), while another study of seed mass ranging from 4.000 to $17.000 \mathrm{mg}$ exhibited positive impacts of seed mass on seed germination (van Mölken et al., 2005). Similarly, a higher seed germination was observed for seven Asteraceae species from Argentina with larger seeds (mass $>0.100 \mathrm{mg}$ ) (Galindez et al., 2009). In the present study, the mass of seeds ranged from 0.076 to $13.890 \mathrm{mg}$, which is comparable to that of seeds investigated by van Mölken (2005). In particular, the present study found that the impacts of seed mass on seed germination varied among different snow treatments. Under the snow addition treatment, seed mass had a significant influence on seed germination, with heavy seeds showing a higher seed germination compared to light seeds. This observation may be due to seedlings of heavy seeds having access to greater amounts of food reserves, thereby resulting in a considerable competitive advantage during drought conditions by allowing a delay in germination or dormancy under unfavorable environment conditions that maximizes plant fitness. In summary, the results of the present study indicate that seed germination of the 35 species investigated under a scenario of climate change in the temperate desert was largely dependent on seed mass.

In the present study, elongated and flat seeds showed a higher GP than round seeds. Although there have been few studies relating seed germination with seed shape (Grime et al., 1981; Liu et al., 2013; Wang et al., 2016), the available results consistently showed that elongated and flat seeds exhibit a higher GP. Many previous studies have shown that seed shape is linked to plant phylogeny, indicating that elongated and flat seeds usually promote fast germination to avoid predation and risks of mortality during dispersal (Thompson et al., 1993; Thompson et al., 1998; Funes et al., 1999).

In the Gurbantunggut Desert, plant ecological characteristics had different impacts on seed germination, with plant life form significantly affecting seed germination and plant ecotype having no impacts. The impacts of plant life form on seed germination may be related to plant habitat or flora, and the impacts vary among different studies. For instance, plant life form, including woody plants, graminoid plants and forbs, had no impacts on seed germination in 109 species in a temperate sandy desert in northeastern China (Wang et al., 2016). Similarly, results from an alpine grassland in Tibet of China showed no differences in seed germination between annuals and perennials for 134 species (Xu et al., 2014). In contrast, significant plant life form impacts on seed germination have been reported in grasslands (Rees, 1994) and alpine meadows (Bu et al., 2008).

\section{Conclusions}

Snow variations had no significant impacts on seed germination of the 35 plant species common to the Gurbantunggut Desert in Central Asia. The similar seed germination observed between the snow addition and ambient snow treatments suggests that slight changes in soil water content and temperature under the snow addition treatment exerted no impacts on seed germination. However, the observation of no significant impacts of the snow removal treatment on seed germination was due to the enough spring precipitation having occurred, which countered the impacts of different water availability under the different snow treatments in the present study. In general, snow 
treatments, seed traits and plant ecotype had no interactive effects on seed germination. Nevertheless, when comparing the relationships between seed germination and seed mass among the three snow treatments, the repression slope under the snow addition treatment was significantly higher, whereas it was significantly lower under the snow removal treatment, compared with that under the ambient snow treatment. The results suggest that snow treatment impacts on seed germination were obvious for heavy seeds in the desert ecosystem. The results of the present study indicate that under a scenario of climate change, variations in snow cover would change plant community structure by changing seed germination of heavy seeds, while the influence on seed germination of light seeds was not significant.

\section{Acknowledgements}

The study was supported by the National Natural Science Foundation of China (41571256, 31670007). Two anonymous reviewers provided comments that improved the manuscript. We thank Dr. CHENG Junhui from Xinjiang Agricultural University for his valuable advice on R language analysis.

\section{References}

Abbott L B, Roundy B A. 2003. Available water influences field germination and recruitment of seeded grasses. Journal of Range Management, 56(1): 56-64.

Arfin-Khan M A S, Vetter V M S, Reshi Z A, et al. 2018. Factors influencing seedling emergence of three global invaders in greenhouses representing major eco-regions of the world. Plant Biology, 20(3): 610-618.

Baskin J M, Baskin C C, Li X J. 2000. Taxonomy, anatomy and evolution of physical dormancy in seeds. Plant Species Biology, 15(2): 139-152.

Bilbrough C J. 2000. Early spring nitrogen uptake by snow-covered plants: A comparison of Arctic and alpine plant function under the snowpack. Arctic, Antarctic, and Alpine Research, 32(4): 404-411.

Blomberg S P, Garland T, Ives A R. 2003. Testing for phylogenetic signal in comparative data: Behavioral traits are more labile. Evolution, 57(2): 717-745.

Bu H Y, Chen X L, Xu X L, et al. 2007. Seed mass and germination in an alpine meadow on the eastern Tsinghai-Tibet plateau. Plant Ecology, 191(1): 127-149.

Bu H Y, Du G Z, Chen X L, et al. 2008. Community-wide germination strategies in an alpine meadow on the eastern Qinghai-Tibet plateau: Phylogenetic and life-history correlates. Plant Ecology, 195(1): 87-98.

Catoni R, Granata M U, Sartori F, et al. 2015. Corylus avellana responsiveness to light variations: Morphological, anatomical, and physiological leaf trait plasticity. Photosynthetica, 53(1): 1-12.

Chao X X, Sun Y. 2016. Effects of different treatments on Nymphoides indica seed germination. Chinese Agricultural Science Bulletin, 32(34): 80-84. (in Chinese)

Chen W N, Chen F J, Xie Y H. 2013. Effects of snowmelt time on growth of Fritillaria unibracteata. Hubei Agricultural Sciences, 52(4): 868-872. (in Chinese)

Chen Z H, Peng J F, Zhang D M, et al. 2002. Seed germination and storage of woody species in the lower subtropical forest. Acta Botanica Sinica, 44(12): 1469-1476.

Constable J V H, Peffer B J, DeNicola D M. 2007. Temporal and light-based changes in carbon uptake and storage in the spring ephemeral Podophyllum peltatum (Berberidaceae). Environmental and Experimental Botany, 60(1): 112-120.

Decker K L M, Wang D, Waite C, et al. 2003. Snow removal and ambient air temperature effects on forest soil temperatures in northern Vermont. Soil Science Society of America Journal, 67(4): 1234-1242.

Dorrepaal E, Aerts R, Corenlissen J H, et al. 2004. Summer warming and increased winter snow cover affect Sphagnum fuscum growth, structure and production in a sub-arctic bog. Global Change Biology, 10(1): 93-104.

Drescher M, Thomas S C. 2013. Snow cover manipulations alter survival of early life stages of cold-temperate tree species. Oikos, 122(4): 541-554.

Drescher M. 2014. Snow cover manipulations and passive warming affect post-winter seed germination: A case study of three cold-temperate tree species. Climate Research, 60(3): 175-186. 
Fan L L, Ma J, Wu L F, et al. 2012. Response of the herbaceous layer to snow variability at the south margin of the Gurbantonggut Desert of China. Chinese Journal of Plant Ecology, 36(2): 126-135. (in Chinese)

Fan L L, Li Y, Tang L S, et al. 2013. Combined effects of snow depth and nitrogen addition on ephemeral growth at the southern edge of the Gurbantunggut Desert, China. Journal of Arid Land, 5(4): 500-510.

Fan L L, Tang L S, Wu L F, et al. 2014. The limited role of snow water in the growth and development of ephemeral plants in a cold desert. Journal of Vegetation Science, 25(3): 681-690.

Figueroa J A. 2003. Seed germination in temperate rain forest species of southern Chile: Chilling and gap-dependency germination. Plant Ecology, 166(2): 227-240.

Frenner M. 2000. Seeds: The Ecology of Regeneration in Plant Communities. New York: CABI Publishing, 31-57.

Funes G, Basconcelo S, Diaz S, et al. 1999. Seed size and shape are good predictors of seed persistence in soil in temperate mountain grasslands of Argentina. Seed Science Research, 9(4): 341-345.

Galindez G, Ortega-Baes P, Daws M I, et al. 2009. Seed mass and germination in Asteraceae species of Argentina. Seed Science and Technology, 37(3): 786-790.

Gordon E. 1998. Seed characteristics of plant species from riverine wetlands in Venezuela. Aquatic Botany, 60(4): 417-431.

Gornish E S, Aanderud Z T, Sheley R L, et al. 2015. Altered snowfall and soil disturbance influence the early life stage transitions and recruitment of a native and invasive grass in a cold desert. Oecologia, 177(2): 595-606.

Gremer J R, Venable L D. 2014. Bet hedging in desert winter annual plants: Optimal germination strategies in a variable environment. Ecology Letters, 17(3): 380-387.

Grime J P, Mason G, Curtis A V, et al. 1981. A comparative study of germination characteristics in a local flora. Journal of Ecology, 69(3): 1017-1059.

Gutterman Y. 2000. Phenotypic effects on seeds during development. In: Fenner M. Seeds: The Ecology of Regeneration in Plant Communities (2 ${ }^{\text {nd }}$ ed.). Wallingford: CABI Publishing, 25-77.

Hendry L B, Shucksmith J, Love J G, et al. 1993. Young People's Leisure and Lifestyle. New Yock: Routledge, $1985-1989$.

Houle G. 2002. The advantage of early flowering in the spring ephemeral annual plant Floerkea proserpinacoides. New Phytologist, 154(3): 689-694.

Huang G, Li Y. 2015. Phenological transition dictates the seasonal dynamics of ecosystem carbon exchange in a desert steppe. Journal of Vegetation Science, 26(2): 337-347.

Huang G, Li Y, Padilla F M. 2015. Ephemeral plants mediate responses of ecosystem carbon exchange to increased precipitation in a temperate desert. Agricultural and Forest Meteorology, 201(15): 141-152.

Huang G, Su Y G, Zhu L, et al. 2016. The role of spring ephemerals and soil microbes in soil nutrient retention in a temperate desert. Plant and Soil, 406(1-2): 43-54.

Huang G, Chen H L, Li Y. 2018. Phenological responses to nitrogen and water addition are linked to plant growth patterns in a desert herbaceous community. Ecology and Evolution, 8(10): 5139-5152.

Jia F Q, Zhang Y M, Tashpolat T, et al. 2017. Effect of snow thickness on seed germination of four ephemeral plants from the Gurbantunggut Desert of China. Seed, 36(2): 24-29. (in Chinese)

Keller F, Goyette S, Beniston M. 2005. Sensitivity analysis of snow cover to climate change scenarios and their impact on plant habitats in alpine terrain. Climatic Change, 72(3): 299-319.

Kreyling J, Haei M, Laudon H. 2012. Absence of snow cover reduces understory plant cover and alters plant community composition in boreal forests. Oecologia, 168(2): 577-587.

Lapointe L L L, Lerat S L S. 2006. Annual growth of the spring ephemeral Erythronium americanum as a function of temperature and mycorrhizal status. Canadian Journal of Botany, 84(1): 39-48.

Li X H, Jiang D M, Liu Z M, et al. 2006a. Germination strategies and patterns of annual species in the temperate semiarid region of China. Arid Land Research and Management, 20(3): 195-207.

Li X H, Jiang D M, Liu Z M, et al. 2006b. Seed germination characteristics of annual species in temperate semi-arid region. Acta Ecologica Sinica, 26(4): 1194-1199. (in Chinese)

Liu H L, Zhang D Y, Duan S M, et al. 2014. The relationship between diaspore characteristics with phylogeny, life history traits, and their ecological adaptation of 150 species from the cold desert of Northwest China. The Scientific World Journal, 
2014(3): 149-168.

Liu Y X. 1992. Flora in Desertis Reipublicae Populorum Sinarum. Beijing: Science Press, 464. (in Chinese)

Liu Z M, Li X H, Li R P, et al. 2003. A comparative study on seed germination of 15 grass species in Keeqin Sandyland. Chinese Journal of Applied Ecology, 14(9): 1416-1420. (in Chinese)

Liu Z M, Li X H, Li R P, et al. 2004. A comparative study of seed germination for 31 annual species of the Horqin steppe. Acta Ecologica Sinica, 24(3): 648-653. (in Chinese)

Liu Z M, Jiang D M, Yan Q L, et al. 2005. Study on dispersal biology of common species of flora of the Horqin Steppe. Acta Prataculturae Sinica, 14(6): 23-33. (in Chinese).

Liu Z M, Yan Q L, Li X H, et al. 2007. Seed mass and shape-germination and plant abundance in a desertified grassland in northeastern Inner Mongolia. Journal of Arid Environments, 69(2): 198-211.

Lorenzi H. 2002. Brazilian Trees: A Guide to the Identification and Cultivation of Brazilian Native Trees, Nova Odessa. São Paulo: Instituto Plantarum de Estados da Flora, 352. (in Portuguese)

Moles A T, Hodson D W, Webb C J. 2000. Seed size and shape and persistence in the soil in the New Zealand flora. Oikos, 89(3): 541-545.

Pagel M. 1999. Inferring the historical patterns of biological evolution. Nature, 401(28): 877-884.

Paradis E, Claude J, Strimmer K. 2004. APE: Analyses of phylogenetics and evolution in R language. Bioinformatics, 20(2): 289-290.

Paz H, Mazer S J, Martinez-Ramos M. 1999. Seed mass, seedling emergence, and environmental factors in seven rain forest Psychotria (Rubiaceae). Ecology, 80(5): 1594-1606.

Pinheiro J, Bates D, DebRoy S, et al. 2019. Nlme: Linear and Nonlinear Mixed Effects Models. [2020-08-23]. https://cran.rproject.org/package $=$ nlme.

Rees M. 1994. Delayed germination of seeds: A look at the effects of adult longevity, the timing of reproduction, and population age/stage structure. American Naturalist, 144(1): 43-64.

Reich P B. 1994. Seed mass effects on germination and growth of diverse European Scots pine populations. Canadian Journal of Forest Research, 24(2): 306-320.

Simons A M, Goulet J M, Bellehumeur K F. 2010. The effect of snow depth on overwinter survival in Lobelia inflata. Oikos, 119(10): 1685-1689.

Soriano D, Orozco-Segovia A, Márquez-Guzmán J, et al. 2011. Seed reserve composition in 19 tree species of a tropical deciduous forest in Mexico and its relationship to seed germination and seedling growth. Annals of Botany, 107(6): 939-951.

Sun Y, Zhang T, Tian C Y, et al. 2009. Response of grass growth and productivity to enhanced water input in Gurbantunggut Desert. Acta Ecologica Sinica, 29(4): 1859-1868. (in Chinese)

Tekrony D M, Shande T, Rucker M, et al. 2005. Effect of seed shape on corn germination and vigour during warehouse and controlled environmental storage. Seed Science and Technology, 33(1): 185-197.

Thompson K, Band S R, Hodgson J G. 1993. Seed size and shape predict persistence in soil. Functional Ecology, 7(2): $236-241$.

Thompson K, Bakker J, Bekker R M, et al. 1998. Ecological correlates of seed persistence in soil in the North-West European flora. Journal of Ecology, 86(1): 163-169.

van Mölken T, Jorritsma-Wienk L D, van Hoek P H W, et al. 2005. Only seed size matters for germination in different populations of the dimorphic Tragopogon pratensis subsp. pratensis (Asteraceae). American Journal of Botany, 92(3): $432-437$.

Wang J H, Baskin C C, Cui X L, et al. 2009. Effect of phylogeny, life history and habitat correlates on seed germination of 69 arid and semi-arid zone species from Northwest China. Evolutionary Ecology, 23(6): 827-846.

Wang Z N, Wang L X, Liu Z M, et al. 2016. Phylogeny, seed trait, and ecological correlates of seed germination at the community level in a degraded sandy grassland. Frontiers in Plant Science, 7(351): 1532-1562.

Webb C O, Donoghue M J. 2005. Phylomatic: Tree assembly for applied phylogenetics. Molecular Ecology Notes, 5(1): 181-183.

Weiher E, van der Werf A, Thompson K R, et al. 1999. Challenging Theophrastus: A common core list of plant traits for functional ecology. Journal of Vegetation Science, 10(5): 609-620. 
Weltzin J F, Mcpherson G R. 2000. Implications of precipitation redistribution for shifts in temperate savanna ecotones. Ecology, 81(7): 1902-1913.

Westoby M, Jurado E, Leishman M R. 1992. Comparative evolution ecology of seed size. Trends in Ecology \& Evolution, 7(11): 368-372.

Wu G L, Du G Z. 2007. Germination is related to seed mass in grasses (Poaceae) of the eastern Qinghai-Tibetan Plateau, China. Nordic Journal of Botany, 25(5-6): 361-365.

Xu J, Li W L, Zhang C H, et al. 2014. Variation in seed germination of 134 common species on the eastern Tibetan Plateau: phylogenetic, life history and environmental correlates. PLoS ONE, 9(6): e98601, doi: 10.1371/journal.pone.0098601.

Yan D R, Bai W C, Bao C, et al. 2012. The factors influencing natural regeneration of Pinus sylvestris var. mongolica in sandy land. Journal of Inner Mongolia Forestry Science and Technology, 38(4): 47-50. (in Chinese)

Yuan S F, Tang H P. 2010. Patterns of ephemeral plant communities and their adaptations to temperature and precipitation regimes in Dzungaria Desert, Xinjiang. Biodiversity Science, 18(4): 346-354. (in Chinese)

Zanne A E, Tank D C, Cornwell W K, et al. 2014. Three keys to the radiation of angiosperms into freezing environments. Nature, 506(56): 89-92.

Zhang L Y, Chen C D. 2002. Study on the general characteristics of plant diversity of Gurbantunggut sandy desert. Acta Ecologica Sinica, 22(11): 1923-1932. (in Chinese)

Zhao J, Song Y, Sun T, et al. 2012. Response of seed germination and seedling growth of Pinus koraiensis and Quercus mongolica to comprehensive action of warming and precipitation. Acta Ecologica Sinica, 32(24): 7791-7800. (in Chinese)

Zheng Y, Xie Z, Yu Y, et al. 2005. Effects of burial in sand and water supply regime on seedling emergence of six species. Annals of Botany, 95(7): 1237-1245. 